\title{
Purine-rich foods: an innocent bystander of gout attacks?
}

\author{
Pascal Richette, Thomas Bardin
}

The natural history of gout typically consists of three periods in a continuum: asymptomatic hyperuricaemia, episodes of acute attacks of gout with asymptomatic intervals, and chronic gouty arthritis. ${ }^{1}$ The last decade has seen major advances in our knowledge of acute attacks of gout with the discovery of the pivotal role of interleukin 1 (IL- 1$){ }^{2}$ however, the mechanisms that trigger acute flares are still poorly known. For instance, despite the incidence of gout increasing exponentially with increasing urate levels, ${ }^{3}$ why gout develops in only a few patients with asymptomatic hyperuricaemia is unclear. In addition, we do not know why acute attacks of gout are so sporadic in patients with established tophaceous gout, despite their massive total body urate load.

In this context, the elegant report from Zhang et al ${ }^{4}$ published in this issue adds a piece of the puzzle to help unravel the mystery of acute attacks of gout. Indeed, this report shows for the first time, that high purine intake, in addition to being a well-known long-term risk factor of urate deposition, also increases the risk of gout attacks almost fivefold among patients with gout. The natural question resulting from this work is: How does acute purine intake trigger acute attacks of gout?

\section{MONOSODIUM URATE (MSU) CRYSTALS WITHIN THE JOINT: NECESSARY BUT NOT SUFFICIENT FOR ACUTE FLARES}

Uric acid is the final metabolite of endogenous and dietary purine metabolism. At a physiologic $\mathrm{pH}$ of 7.4 in the extracellular compartment, $98 \%$ of uric acid is in the ionised form of urate. Because of the high concentration of sodium in the extracellular compartment, urate is largely present as MSU, with a

Hôpital Lariboisière, Fédération de Rhumatologie, Université Paris 7, UFR médicale, Assistance PubliqueHôpitaux de Paris, Paris Cedex 10, France

Correspondence to Professor Pascal Richette, Fédération de Rhumatologie, Hôpital Lariboisière, 2 Rue Ambroise Paré, 75475 Paris cedex 10, France; pascal.richette@lrb.aphp.fr low solubility limit, approximately $380 \mu \mathrm{mol} / 1$ at $37^{\circ} \mathrm{C}$. When urate concentration exceeds the saturation point, the risk of MSU crystal formation and precipitation increases. ${ }^{1}$

Ultrasound studies have shown that about $20 \%-25 \%$ of asymptomatic patients with hyperuricaemia have urate deposits in the joints or tendons of their lower limbs. ${ }^{5} 6$ In addition, MSU crystals can be identified in synovial fluid from asymptomatic joints, especially the knees and the first metatarsophalangeal joints. ${ }^{7}$ Therefore, MSU crystals within the joints are necessary, but not sufficient enough to trigger acute attacks of gout.

\section{ACUTE ATTACKS OF GOUT CAN BE TRIGGERED BY A RAPID DECREASE IN URATE LEVELS}

The best-known trigger of acute attacks of gout is a decreased level of urate in patients with previously formed urate deposits. Rapid dissolution of urate deposits is believed to favour crystal shedding in the joint space. Triggered acute attacks during the first months of uratelowering therapy (ULT) in gouty patients has been known for a long time and has been recently confirmed by pivotal studies of febuxostat and pegloticase. The number and severity of ULT-induced flares depend on both baseline urate values and velocity of the urate level reduction. $^{89}$ To avoid this increased incidence of gout flares, prophylaxis with low-dose colchicine or non-steroidal antiinflammatory drugs is recommended for 6 months after the initiation of ULT. Other factors that can trigger acute attacks of gout, presumably through a transient decrease in urate levels, are the post-surgical period, ${ }^{10} 11$ whisky intake $e^{13}$ and systemic inflammation. How these factors lead to reduced urate levels may be diverse. A rapid drop in urate levels after surgery might be due to the low sodium loading in infusion fluid during the peri-surgical period, ${ }^{10}$ whereas, the uricosuric property of whisky ${ }^{13}$ and IL- $6,{ }^{14}$ a cytokine produced during numerous inflammatory conditions, including acute flares, can explain their urate-lowering effects. Of note, uricaemia is frequently decreased during gout attacks, sometimes to within the normal range. $^{15} 16$

\section{PURINE INTAKE AND GOUT}

Urate levels increase greatly after intake of fructose-rich food, which induces production of uric acid by increasing the degradation of ATP to AMP, a uric acid precursor, ${ }^{17}$ as well as after intake of a large amount of purine. ${ }^{18}$ The association of chronic intake of purine-rich foods, mainly of animal origin, and incident gout, is well established. ${ }^{19}$ The study by Zhang et $a l^{4}$ published in this issue now provides evidence that acute purine intake is also associated with acute gout flare. This online case-crossover study investigated within a short time the relation between dietary factors and risk of recurrent gout attacks. Data are from 633 patients with gout, who were queried about food intake during the 2-day period prior to an attack of gout, as well as at different time points used as control periods. About $61 \%$ of participants consumed alcohol, 29\% used diuretics, and $45 \%$ took allopurinol. The median amount of purine intake over a 2-day control period was $1.66 \mathrm{~g}$, that is, the equivalence of $1.4 \mathrm{~kg}$ of beef. By comparison with the lowest quintile of total purine intake over a 2-day period, with each increasing quintile, the ORs for recurrent gout attacks were 1.17, 1.38, 2.21 and 4.76, respectively. Interestingly, the impact of purine on risk of gout attacks was substantially smaller with plant than animal purine sources. These data agree well with a previous study that found no association of long-term consumption of purine-rich vegetables and risk of incident gout. ${ }^{19}$ Unfortunately, the design of this study precluded the collection of blood to determine urate levels, but acute purine intake in these patients could have induced at least a transient increase in urate levels that coincided with the initiation of flares. Other factors known to increase urate levels and that have been reported to trigger acute attacks of gout, include alcohol intake ${ }^{20}$ and recent diuretic use. ${ }^{21}$ Of note, these data were obtained from the same online case-crossover study, and also lack details on urate levels.

\section{HOW MIGHT PURINE INTAKE TRIGGER ACUTE ATTACKS OF GOUT?}

In tissues, MSU crystal formation depends on several factors, particularly, the local concentration of urate. The solubility of urate in joint fluids also depends 
on the articular hydration state, temperature, $\mathrm{pH}$, concentration of cations and presence of extracellular matrix proteins such as proteoglycans, collagens and chondroitin sulphate. ${ }^{1}$ An increase in urate levels per se cannot trigger flares, as has been well demonstrated with intra-articular injections of uric acid not inducing inflammatory arthritis, as compared with MSU crystal injections. ${ }^{22}$ In addition, and in contrast with MSU crystal dissolution which occurs rapidly after urate lowering, nucleation and then crystal growth is slow. The growth of crystals usually seen by polarised light microscopy usually takes months or years, ${ }^{23}$ so a transient increase in urate levels after, for example, high purine intake, is unlikely to acutely promote crystal formation. By contrast, a decrease in urate levels will be followed by rapid dissolution of synovial tophi within joints that will lead to crystal shedding, and facilitates the interaction of crystals with the synovial cell lining and residential inflammatory cells.

Thus, acute high purine intake is unlikely to trigger flare by acute crystallisation of MSU in synovial fluid. Therefore, one hypothesis could be that other components of meat and seafood could be responsible for triggering gout attacks. Potential candidates include high levels of free fatty acids (FFAs), which are increased after heavy eating or alcohol consumption. ${ }^{24}$ Indeed, Joosten et al, ${ }^{25}$ besides others, ${ }^{26}$ demonstrated that pure MSU crystals alone could not induce IL-1 $\beta$ production from primary human peripheral blood mononuclear cells, or from mouse peritoneal macrophages. They have shown that the 18-carbon fatty acid was the most effective lipid for stimulating IL-1 $\beta$ in combination with MSU crystals. FFAs, in the presence of MSU crystals, induced a substantial release of IL-1 $\beta$ after the engagement of Toll-like receptor 2 (TLR2) but not TLR4, and this effect depended on activation of caspase 1 and Apoptosis-associated speck-like protein containing a CARD (ASC) but not NALP3, a finding that differed from that reported by others. ${ }^{2}$ According to Dinarello, these results suggest that MSU crystals need a second signal for inducing IL-1 $\beta$ via TLR2, the signal being an increase in levels of serum lipids, thus allowing for the synthesis, processing and release of IL- $1 \beta$, and initiating clinical inflammation. ${ }^{27}$ Studies of dietary products able to acutely increase urate levels but containing no FFAs would be of interest to test whether the intake of FFAs and not purine, triggers gout attacks.

\section{CONCLUSIONS}

Purine-rich food intake is associated with both incident and acute attacks of gout. Long-term purine intake, by increasing urate levels, can lead to gout. However, given the slow process of both nucleation and MSU crystal growth, a transient increase in urate levels with purine intake is unlikely to be directly pathogenic. Purine may be an innocent bystander in acute attacks of gout, which could be triggered by FFAs, for example, in some purine-rich foods.

Funding This work was funded (copyediting) by the 'Association Rhumatisme et Travail' (Rheumatology department, Lariboisière Hospital, Paris, France).

\section{Competing interests None.}

Provenance and peer review Not commissioned; externally peer reviewed.

Accepted 24 June 2012

Published Online First 17 July 2012

Ann Rheum Dis 2012;71:1435-1436.

doi:10.1136/annrheumdis-2012-201838

\section{REFERENCES}

1. Richette $\mathbf{P}$, Bardin T. Gout. Lancet 2010;375:318-28

2. Martinon F, Petrilli V, Mayor A, et al. Gout-associated uric acid crystals activate the NALP3 inflammasome. Nature 2006:440:237-41.

3. Roddy E, Doherty M. Epidemiology of gout. Arthritis Res Ther 2010;12:223.

4. Zhang $\mathbf{Y}$, Chen $\mathrm{C}$, Choi $\mathrm{H}$, et al. Purine-rich foods intake and recurrent gout attacks. Ann Rheum Dis 2012. Published Online First 30 May 2012. doi:10.1136/ard-2011-201215

5. Pineda C, Amezcua-Guerra LM, Solano C, et al. Joint and tendon subclinical involvement suggestive of gouty arthritis in asymptomatic hyperuricemia: an ultrasound controlled study. Arthritis Res Ther 2011;13:R4.

6. Puig JG, de Miguel E, Castillo MC, et al. Asymptomatic hyperuricemia: impact of ultrasonography. Nucleosides Nucleotides Nucleic Acids 2008:27:592-5.

7. Pascual E, Doherty M. Aspiration of normal or asymptomatic pathological joints for diagnosis and research: indications, technique and success rate. Ann Rheum Dis 2009;68:3-7.

8. Becker MA, Schumacher HR Jr, Wortmann RL, et al. Febuxostat compared with allopurinol in patients with hyperuricemia and gout. N Engl J Med 2005;353:2450-61.
9. Sundy JS, Baraf HS, Yood RA, et al. Efficacy and tolerability of pegloticase for the treatment of chronic gout in patients refractory to conventional treatment: two randomized controlled trials. JAMA 2011; 306:711-20.

10. Kang EH, Lee EY, Lee YJ, et al. Clinical features and risk factors of postsurgical gout. Ann Rheum Dis 2008;67:1271-5.

11. Friedman JE, Dallal RM, Lord JL. Gouty attacks occur frequently in postoperative gastric bypass patients. Surg Obes Relat Dis 2008:4:11-3.

12. Vandenberg MK, Moxley G, Breitbach SA, et al. Gout attacks in chronic alcoholics occur at lower serum urate levels than in nonalcoholics. J Rheumatol 1994;21:700-4.

13. Nishioka K, Sumida T, Iwatani M, et al. Influence of moderate drinking on purine and carbohydrate metabolism. Alcohol Clin Exp Res 2002;26:20S-5S.

14. Urano W, Yamanaka $\mathrm{H}$, Tsutani $\mathrm{H}$, et al. The inflammatory process in the mechanism of decreased serum uric acid concentrations during acute gouty arthritis. J Rheumatol 2002;29: 1950-3.

15. Schlesinger N, Norquist JM, Watson DJ. Serum urate during acute gout. J Rheumatol 2009;36:1287-9.

16. Logan JA, Morrison E, McGill PE. Serum uric acid in acute gout. Ann Rheum Dis 1997;56:696-7.

17. Choi HK, Willett W, Curhan G. Fructose-rich beverages and risk of gout in women. JAMA 2010;304:2270-8

18. Clifford A, Riumallo J, Young $\mathrm{V}$, et al. Effect of oral purines on serum and urinary uric acid of normal, hyperuricemic and gouty humans. J Nutr 1976;106:428-34.

19. Choi HK, Atkinson K, Karlson EW, et al. Purine-rich foods, dairy and protein intake, and the risk of gout in men. N Engl J Med 2004;350:1093-103.

20. Zhang $\mathbf{Y}$, Woods R, Chaisson CE, et al. Alcohol consumption as a trigger of recurrent gout attacks. Am J Med 2006:119:e13-18.

21. Hunter DJ, York M, Chaisson CE, et al. Recent diuretic use and the risk of recurrent gout attacks: the online case-crossover gout study. J Rheumatol 2006:33:1341-5.

22. McCarty DJ Jr. Mechanisms of the crystal deposition diseases-gout and pseudogout. Ann Intern Med 1973;78:767-71.

23. Fiddis RW, Vlachos N, Calvert PD. Studies of urate crystallisation in relation to gout. Ann Rheum Dis 1983:42(Suppl 1):12-5.

24. Lopes SM, Trimbo SL, Mascioli EA, et al. Human plasma fatty acid variations and how they are related to dietary intake. Am J Clin Nutr 1991;53. 628-37.

25. Joosten LA, Netea MG, Mylona E, et al. Engagement of fatty acids with Toll-like receptor 2 drives interleukin-1 beta production via the ASC/ caspase 1 pathway in monosodium urate monohydrate crystal-induced gouty arthritis. Arthritis Rheum 2010;62:3237-48.

26. Giamarellos-Bourboulis EJ, Mouktaroudi M, Boda $\mathrm{E}$, et al. Crystals of monosodium urate monohydrate enhance lipopolysaccharide-induced release of interleukin 1 beta by mononuclear cells through a caspase 1-mediated process. Ann Rheum Dis 2009;68:273-8.

27. Dinarello CA. How interleukin-1 beta induces gouty arthritis. Arthritis Rheum 2010;62:3140-4. 